\section{Tacrolimus in non-Asian patients with SLE: a real-life experience from three European centres}

Chiara Tani, ${ }^{1,2,3}$ Elena Elefante, ${ }^{1,2,3}$ Miguel Martin-Cascón, ${ }^{1,2,3}$ Meriem Belhocine, ${ }^{1,2,3}$ Cristina Lavilla Olleros, ${ }^{1,2,3}$ Roberta Vagelli, ${ }^{1,2,3}$ Chiara Stagnaro, ${ }^{1,2,3}$ Nathalie Costedoat-Chalumeau, ${ }^{1,2,3}$ Guillermo Ruiz-Irastorza, ${ }^{1,2,3}$ Marta Mosca ${ }^{1,2,3}$

To cite: Tani C, Elefante E, Martin-Cascón M, et al. Tacrolimus in non-Asian patients with SLE: a real-life experience from three European centres. Lupus Science \& Medicine 2018;5:e000274. doi:10.1136/ lupus-2018-000274

The present manuscript is based on work previously presented at the ACR in 2017. A conference and published as a conference abstract should state this in the Acknowledgements section. TC, MM-C, BM, VR, SC, R-IG, C-CN, MMT in Non-Asian Systemic Lupus Erythematosus Patients: A Real-Life Experience from Three European Centers. Arthritis Rheumatol. 2017; 69 (suppl 10).

Received 3 May 2018

Revised 2 July 2018

Accepted 6 July 2018

Check for updates

(c) Author(s) (or their employer(s)) 2018. Re-use permitted under CC BY-NC. No commercial re-use. See rights and permissions. Published by BMJ.

For numbered affiliations see end of article.

Correspondence to

Dr Marta Mosca; marta.mosca@ med.unipi.it

\section{ABSTRACT}

Objectives To analyse the real-life practice on the use of Tacrolimus (TAC) in patients with systemic lupus erythematosus (SLE) from three European SLE referral centres.

Methods Adult patients with SLE regularly followed at three European referral centres were included. Demographics, cumulative organ involvement, treatment history, Systemic

Lupus Disease Activity Index (SLEDAl), laboratory features and physician's judgement were collected at baseline and at 3-6-12 months after starting TAC.

Results 29 patients were included ( $89 \%$ female, mean age $38 \pm 9$ years). Ethnicity was predominantly Caucasian $(82 \%)$, Black African (11\%), Hispanic (3.5\%) and Caribbean (3.5\%). The main indications for TAC prescription were renal involvement $(82.7 \%)$, arthritis $(10.3 \%)$, cutaneous manifestations $(6.8 \%)$, haematological manifestations (6.8\%), serositis (3.4\%). At 3 months, there was a clinical improvement in 21 patients $(72.4 \%)$ and 9 of these experienced a complete resolution of symptoms (31\%). This corresponds to: (1) a significant decrease in the mean SLEDAl; (2) a significant decrease in the mean 24 hours proteinuria; a significant increase in C3 and stable creatinine values. At 6 months $(n=25)$, the physician declared an improvement in 19 patients $(76 \%)$ and a complete resolution of symptoms in $9(36 \%)$. The same trend was observed at 12 months of follow-up. TAC was discontinued in nine pts (31\%); reasons for discontinuation were inefficacy (13.8\%), drug intolerance (10\%) and disease remission $(6.9 \%)$.

Conclusions Despite the limitation due to the small number of patients and the uncontrolled nature of the study, these data show that TAC can be considered a valid therapeutic option in patients with SLE, especially for renal involvement.

\section{INTRODUCTION}

Tacrolimus (TAC) is an immunosuppressive drug used worldwide in the field of solid organ transplantation. ${ }^{2}$ Besides its immunosuppressive effect, TAC also exerts an antiproteinuric action and it is therefore used in treating a variety of renal diseases. ${ }^{34}$ In a lupus nephritis (LN) mouse model, TAC seemed to protect podocytes from injury both by stabilising the actin cytoskeleton and by inhibiting apoptosis. $^{5}$

During the last years, there has been a growing interest in the possible role of TAC in the management of systemic lupus erythematosus (SLE). TAC ointment has been found to be effective for severe refractory cutaneous SLE manifestations, and more recently the attention has been focused on the potential role of oral TAC in the management of other SLE manifestations, especially renal. ${ }^{6-8}$

In Asian patients, TAC demonstrated to be effective as remission induction therapy as well as in refractory $\mathrm{LN}^{9-17}$ Less convincing data are available for non-Asian populations. ${ }^{18} 19$ EULAR recommends calcineurin inhibitors (CINs) as an alternative therapy for class $\mathrm{V}$ $\mathrm{LN}$, but uncertainty remains about their role in proliferative disease or in the maintenance of remission. ${ }^{20}$

The aim of this study was to analyse the real-life use of TAC in patients with SLE from three European referral centres.

\section{METHODS}

This is a retrospective analysis of prospectively collected data from three European centres: Rheumatology Unit, University of Pisa, Italy; Autoimmune Diseases Research Unit, BioCruces, Hospital Universitario Cruces, Spain; Centre de référence maladies auto-immunes et systémiques rares d'île de France, Cochin, Paris, France. Adult patients with a diagnosis of SLE according to the 1997 ACR criteria, regularly followed at the three referral centres were included if they received a treatment with TAC for SLE manifestations.

For each patient, demographics, cumulative organ involvement and treatment history as well as concomitant medications were collected. Disease activity was evaluated using the Systemic Lupus Disease Activity Index 
(SLEDAI-2K) score at baseline and at 3-6-12 months after starting TAC; physician's judgement (PJ) at 3,6 , 9, 12 months was defined as 'complete resolution of symptoms', 'partial improvement' or 'no improvement'. Response was defined in presence of at least 'partial improvement' of symptoms.

At the same time-points, the following laboratory data were evaluated: serum creatinine, C3, C4, urinary sediment, anti-dsDNA antibodies. In addition, the presence of clinical or biochemical adverse events was assessed.

In patients who received TAC for LN, the response was evaluated according to the following criteria modified from Appel et al: response (R) was defined as $>50 \%$ proteinuria reduction as compared with initial values and stabilisation or improvement of creatinine with respect to the initial values. Renal response was defined as complete (CR) in the presence of normal creatinine (or return to initial values) with $24 /$ hours proteinuria $<0.5 \mathrm{~g}$ and inactive urinary sediment ( $\leq 5$ white blood cells per highpower field and $\leq 5$ red blood cells per high-power field and a reading of lower than 2 on dipstick and absence of red cell casts). ${ }^{21}$

TAC was started in all patients at increasing dosage from $2 \mathrm{mg} /$ day to $0.06 \mathrm{mg} / \mathrm{kg}$ /day; weekly plasma levels monitoring was performed until reaching the stable target level of $4-6 \mathrm{ng} / \mathrm{mL}$. No dose reductions were required because of adverse events.

Continuous data are reported as median and IQR or as mean and SD as appropriate. Categorical data are reported as percentage. Comparison between groups were performed with Student's t test for paired groups. Statistical analysis was performed with STATA-13 software.

This study has been approved by the local Ethical Committee of the Coordinator centre (Comitato etico Area Vasta Nord Ovest, Azienda ospedaliero-Universitaria Pisana, protocol number 13855).

\section{RESULTS}

Twenty-nine patients were included in this analysis; they were predominantly female $(89 \%)$ with a mean age at enrolment of $38 \pm 9$ years. Mean disease duration was $12.9 \pm 6$ years. Ethnicity was predominantly Caucasian (82\%), Black African (11\%), Hispanic (3.5\%) and Caribbean $(3.5 \%)$. Cumulative clinical and serological manifestations of the enrolled patients are reported in table 1 . Twenty patients $(70 \%)$ completed the 12 months of follow-up; the median duration of the follow-up was 12 months (range 3-12 months).

The main indications for TAC prescription were $\mathrm{LN}$ $(82.7 \%)$, joint manifestations $(10.3 \%)$, skin manifestations $(6.8 \%)$, haematological manifestations $(6.8 \%)$ and serositis $(3.4 \%)$. Three patients suffered lupus activity at two different levels (joint and skin, renal and joint, renal and haematological).

In $65.5 \%$ of patients, TAC was a second-choice treatment either for the failure of, or for the intolerance
Table 1 Clinical manifestations, serological profile and treatments history of the patients

\begin{tabular}{lc}
\hline \multirow{2}{*}{$\begin{array}{l}\text { Disease duration (years, median, } \\
\text { IQR) }\end{array}$} & $\mathbf{1 3 ;} \mathbf{7 . 5 - 1 7}$ \\
\cline { 2 - 2 } Cumulative organ involvement \\
\hline Renal \\
\hline Joint & $27(93.1)$ \\
\hline Skin & $27(93.1)$ \\
\hline Haematological & $19(65.6)$ \\
\hline Serositis & $18(62)$ \\
\hline Neuropsychiatric & $12(41.4)$ \\
\hline Cumulative serology & $2(6.9)$ \\
\hline ANA & \\
\hline Anti-dsDNA & $29(100)$ \\
\hline Anti-RNP & $25(86.2)$ \\
\hline Anti-Sm & $15(51.7)$ \\
\hline aPL & $14(48.3)$ \\
\hline Anti-SSA & $12(41.4)$ \\
\hline Anti-SSB & $11(37.9)$ \\
\hline Previous IS therapies & $3(10.3)$ \\
\hline Azathioprine & \\
\hline Mycophenolate mofetil & $19(65.5)$ \\
\hline Cyclophosphamide & $5(17.2)$ \\
\hline Methotrexate & $21(72.4)$ \\
\hline Rituximab & $5(17.2)$ \\
\hline Belimumab & $12(41.4)$ \\
\hline ANA, & $4(13.8)$ \\
\hline
\end{tabular}

ANA, antinuclear antibodies; Anti-RNP, anti-ribonucleoprotein antibodies; Anti-SSA, anti Ro/SSA antibodies; Anti-SSB, anti-La/SSB antibodies; Anti-dsDNA, anti-double stranded DNA antibodies; aPL, antiphospholipid antibodies; IS, immunosuppressive.

to a previous immunosuppressive (IS) therapy; it was prescribed at a median daily dose of $4.5 \mathrm{mg}$ (IQR 3-5.5).

The median number of previous IS was 2 (IQR 1-3). Previous IS therapies are detailed in table 1.

TAC was prescribed just before $(n=2)$ or during pregnancy as first-line or as a second line treatment in two cases each.

Concomitant medications when TAC was started included glucocorticoids (GC) in 27 patients $(93.1 \%$; median daily dose $7.5 \mathrm{mg}$; IQR 3.75-12.5) and hydroxychloroquine in 24 patients $(82.8 \%)$; as far as immunosuppressants are concerned, TAC was prescribed alone in 16 cases $(55.2 \%)$, while it was associated to mycophenolate mofetil (MMF) in 8 patients (27.6\%), azathioprine in 3 patients $(10.4 \%)$, belimumab in 4 patients $(13.8 \%)$ and rituximab in 2 patients $(6.9 \%)$.

Clinical and serological data at TAC starting and at $3,6,12$ months of follow-up are summarised in table 2 and in figure 1. Briefly, according to PJ assessment, at 3 months, there was a partial clinical improvement in 21 

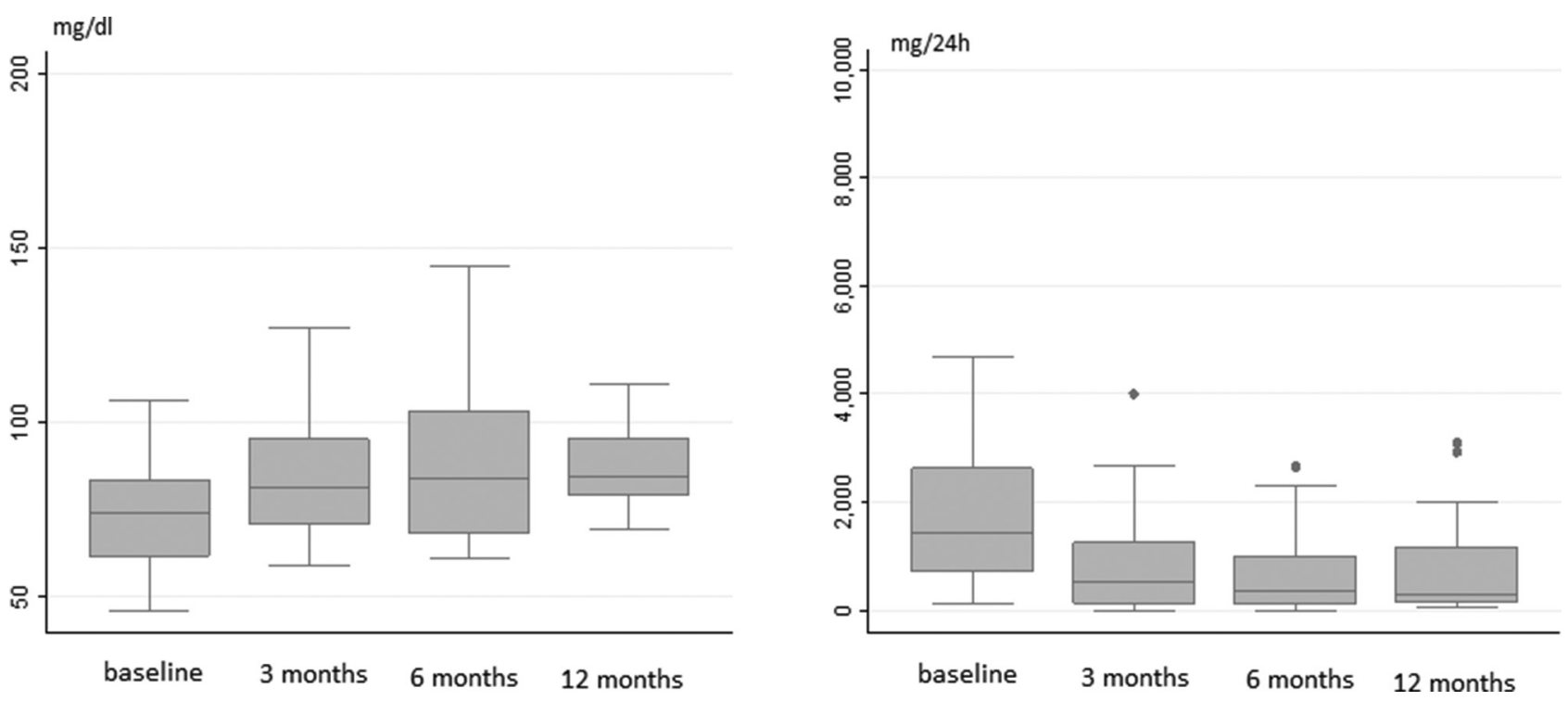

Figure 1 C3 and 24 hours proteinuria at baseline, 3-6-12 months of follow-up.

patients $(72.4 \%)$; complete resolution of clinical features of activity in $9(31 \%)$. Accordingly, a significant decrease in the mean SLEDAI, and a significant increase in mean C3 levels was seen (table 2, figure 1).

Twenty-five patients had a follow-up on TAC of at least 6 months; partial clinical improvement was observed in 19 patients $(76 \%)$ with complete resolution in 9 patients (36\%). At 12 months of follow-up, partial improvement and complete resolution were achieved in $95 \%$ and $55 \%$, respectively, of 20 patients.

Interestingly, among the 21 patients who responded to TAC within 3 months, only 4 of them showed a further clinical improvement at 6 months (from partial to complete response) (figure 2). In addition, all non-responders at
3 months were still non-responders at 6 months or had discontinued treatment because of inefficacy.

\section{Renal involvement}

At TAC initiation, active LN was present in 24 patients $(82.8 \%)$; TAC was prescribed for a renal flare in $18(75 \%$ cases) and for nephritis onset in 6 cases (25\%). Kidney pathology was available for 23 patients: 12 diffuse proliferative LN, 1 localised proliferative LN, 6 membranous $\mathrm{LN}$ and 4 patients with mixed diffuse proliferative and membranous LN. Baseline renal features and at 3, 6 and 12 months of follow-up are shown in table 2. Proteinuria was significantly $(>50 \%)$ decreased at 3 months in 15 patients $(62.5 \%)$; in 4 patients $(16.6 \%)$, the reduction

Table 2 Clinical and serological features at baseline and during the follow-up

\begin{tabular}{|c|c|c|c|c|c|}
\hline & Baseline & $P$ values & $\begin{array}{l}3 \text { months, } n=29 \\
\text { Renal, } n=23\end{array}$ & $\begin{array}{l}6 \text { months, } n=25 \\
\text { Renal, } n=21\end{array}$ & $\begin{array}{l}12 \text { months, } n=20 \text {; } \\
\text { Renal, } n=16\end{array}$ \\
\hline SLEDAI (median \pm IQR) & $8(5.5-12)$ & $<0.001$ & $4(2-6)$ & $4(2-6.5)$ & $3(2-8)$ \\
\hline Renal subgroup & $65(55-74)$ & 0.01 & $79(69-88)$ & $81(71-90)$ & $83(77-92)$ \\
\hline Extrarenal subgroup & $78(62-85)$ & 0.03 & $85(78-95)$ & $86(80-99)$ & $86(81-99)$ \\
\hline Extrarenal subgroup & $68 \%$ & 0.04 & $68 \%$ & $50 \%$ & $20 \%$ \\
\hline Creatinine mg/dl (median \pm IQR) & $0.7(0.5-0.88)$ & n.s. & $0.82(0.6-1.1)$ & $0.9(0.6-1.17)$ & $0.8(0.6-1.07)$ \\
\hline $\begin{array}{l}24 \text { hours proteinuria mg } \\
\text { (median } \pm \mathrm{IQR} \text { ) }\end{array}$ & 1425 (710-2630) & $<0.001$ & $530(135-1250)$ & $350(110-1000)$ & $380(140-1500)$ \\
\hline Renal complete response, N (\%) & & & $8(34 \%)$ & $9(47 \%)$ & $8(50 \%)$ \\
\hline
\end{tabular}

PJ, physician's judgement. 
in proteinuria took 6 months with no further significant improvement recorded thereafter. No data were available for two patients and two additional patients discontinued the therapy before 6 months.

At 3 months $(\mathrm{n}=23)$, a response was observed in 15 patients $(65.2 \%)$ and a complete response was observed in 8 patients $(34.7 \%)$; at 6 months $(\mathrm{n}=21), 16$ patients $(76.2 \%)$ were responders $(42.8 \%$ complete responders), the same trend was maintained at 12 months of follow-up $(\mathrm{n}=16): 14$ responders $(87.5 \%), 8$ complete responders $(50 \%)$ (figure 2).

\section{Extrarenal manifestations}

Extrarenal disease features were present in eight patients (table 3): haematological in six patients $(20.7 \%)$, arthritis in four patients $(13.8 \%)$, serositis in two patients $(6.9 \%)$ and/or cutaneous manifestations in two patients $(6.9 \%)$. Interestingly, a partial or complete resolution of the extrarenal symptoms according to physician global assessment (PGA) was observed in five patients $(62.5 \%)$ and, most importantly, in four of them, the response was achieved within the first 3 months of treatment. In three cases, TAC was ineffective; they were one patient with severe haematological manifestations (Evans syndrome), one patient with skin vasculitis and one patient with arthritis. As a whole, TAC was effective in three out of four cases $(75 \%)$ in whom the main manifestation was arthritis.

We subanalysed the C3 trend in patients who received TAC for extrarenal manifestations and we found a significant increase in C3 levels in all patients.

\section{Safety issues and drug discontinuation}

TAC was discontinued in nine pts $(31 \%)$; reasons for discontinuation were drug intolerance in three cases $(10 \%)$ after a mean of 5.3 months; inefficacy or disease relapse in four cases $(13.8 \%)$ after a mean of 8 months; disease remission in two cases $(6.9 \%)$. In these latter cases, the drug was continued for 12 and 3 years, respectively.

The three patients with adverse drug reactions that caused drug discontinuation had gastrointestinal intolerance, headache and cognitive impairment. In one case, recurrent mild episodes of infections were reported; in this case, TAC had been administered in association with GC and belimumab. No significant increase in creatinine levels was recorded during the follow-up (table 2).

Patients who discontinued TAC because of disease remission remained in remission after drug discontinuation. One of them had a mild renal flare with proteinuria $<1$ g/day 2 years later, when prednisone was discontinued. Remission was easily attained without adding TAC to therapy.

\section{DISCUSSION}

This study describes the use of TAC in a multicentre European lupus cohort, showing that TAC can be a valid therapeutic option also in non-Asian patients with SLE, especially those with LN and women with pregnancy wish.
Although the majority of patients had renal involvement, other manifestations such as arthritis, serositis and cytopenias also improved at a rate similar to $\mathrm{LN}$.

TAC demonstrated a rapid effect on clinical, urinary and serological parameters; in fact, in the majority of the cases, the response was observed within the first 3 months of therapy; a rapid decrease in proteinuria was observed and also a significant increase in complement levels and a reduction of global disease activity. This aspect is very important because a timely evaluation of the results is crucial in a treat to target therapeutic strategy. As far as drug toxicity is concerned, no severe TAC side effects were recorded in our case series.

In our series, TAC was combined with other immunosuppressive drugs (traditional or biologics) in $44 \%$ of the cases. Based on the experience in the field of the organ transplantation, literature data support the use of TAC in combination with other drugs, mainly MMF. ${ }^{22-24}$

Previous experiences on the use of TAC in Asian patients showed that it can be considered a valid alternative to cyclophosphamide (CYC) and MMF for induction therapy in $\mathrm{LN}^{9-14}$ and as a second line treatment in refractory proteinuria ${ }^{15-17}$ as well.

To the best of our knowledge, this is one of the largest series on the use of this drug in non-Asian SLE population. In such ethnic groups, data on combined therapy are conflicting and limited. Gordon et al successfully added TAC to MMF in six patients with LN who failed to respond to MMF therapy, with no treatment-limiting adverse effects. ${ }^{18}$ On the contrary, less encouraging data came from the study of Lanata et al who added TAC (mean daily dose $3.4 \mathrm{mg}$ ) to MMF in seven Caucasian and Afro-American patients with SLE with LN (class III, IV, V alone or combined) refractory to MMF therapy. In this small cohort, toxicity was frequent compared with benefit, limiting the use of combined therapy in these patients. ${ }^{19}$

In our case series, 10 patients had membranous LN; some studies summarised in table 4 support the efficacy of TAC particularly in the histological subtype of class $\mathrm{V}$ LN. ${ }^{25} 26$

Safety concerns, mainly regarding the possible nephrotoxicity and the incidence of hypertension and diabetes during therapy with CINs, may potentially limit the use of TAC in the long-term. Available literature data, however, show a good safety profile of TAC with stable serum creatinine and estimated glomerular filtration rate (eGFR) during prolonged follow-up. ${ }^{27}$

Regarding the potential side effects of inmmunosuppressive drugs, infections are among the most concerning. A recent meta-analysis compared the infectious risk with various immunosuppressive drugs and corticosteroids in patients with LN. The authors showed that TAC was associated with a significantly lower risk of serious infections compared with high doses GC and cyclophosphamide. However, it has to be underlined that all included TAC trials were of small sample size and performed in non-Caucasian patients. ${ }^{28}$ 

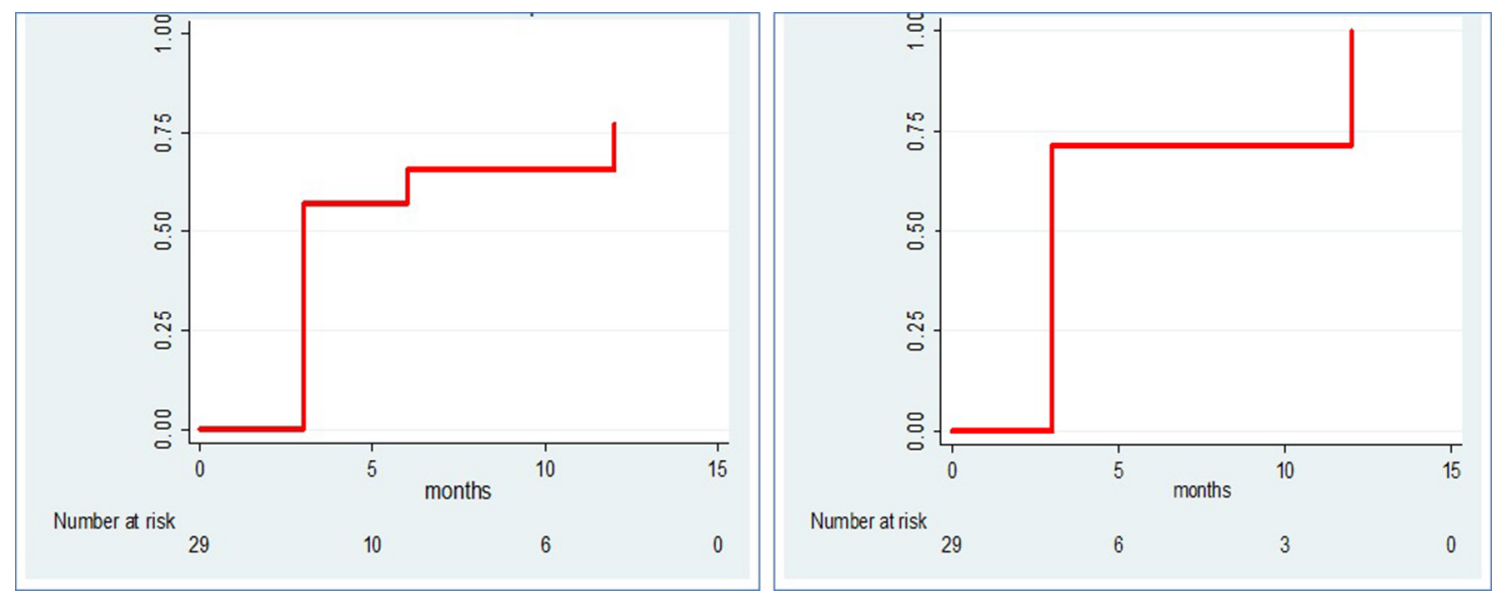

Figure 2 Kaplan-Meier analysis on time to renal response (A) and time to PJ improvement (B). PJ, physician's judgement.

Very little is known about efficacy and safety of TAC for extrarenal SLE manifestations. Small studies in Asian patients suggest that adding TAC without increasing the GC dose may provide an effective treatment option for minor flares in patients with SLE particularly in treating joint, mucocutaneous and haematological manifestations. ${ }^{29-31}$ Our data, despite the small number of patients, support this view.

One interesting finding of this analysis is the positive and rapid effect of TAC on serological parameters; it is well known that TAC exerts an antiproteinuric action through its haemodynamic effect of decreasing glomerular filtration rate by intrarenal vasoconstriction. ${ }^{8}$ Moreover, in a LN mouse model, TAC seems to protect podocytes from injury both by stabilising their actin cytoskeleton and by inhibiting their apoptosis. ${ }^{5}$ Thus, in theory the increased complement levels that we described could be related to a decrease in protein excretion from kidneys. To evaluate this hypothesis, we subanalysed the C3 trend in the small percentage of patients who received TAC for extrarenal manifestations and we found a significant increase in C3 levels in all patients. Thus, even if the little number could only suggest a trend, these data seem to confirm that TAC has got an immunosuppressive effect. Further studies on larger cohort should confirm this observation.

Our study is limited by the retrospective analysis and the small number of patients, particularly those with extrarenal manifestations. However, this is one of the largest group of non-Asian patients reported on a real-life setting. In addition, the three lupus cohorts contributing to this study are well characterised and coming from three different European countries (Italy, Spain and France).

\begin{tabular}{|c|c|c|c|c|c|c|}
\hline $\begin{array}{l}\text { Patient } \\
\text { N, Sex }\end{array}$ & $\begin{array}{l}\text { Age at } \\
\text { TAC } \\
\text { starting } \\
\text { (years) }\end{array}$ & $\begin{array}{l}\text { Disease } \\
\text { duration } \\
\text { (years) }\end{array}$ & $\begin{array}{l}\text { Main indication for } \\
\text { TAC }\end{array}$ & Extrarenal features & $\begin{array}{l}\text { Concomitant } \\
\text { therapies }\end{array}$ & Outcome (PGA) \\
\hline $1, M$ & 18 & 8 & Nephritis & Arthritis, lymphopaenia & $\mathrm{GC}, \mathrm{HCQ}, \mathrm{MMF}$ & $\begin{array}{l}\text { Renal: non-responder; } \\
\text { Extrarenal: non-responder }\end{array}$ \\
\hline $2, F$ & 53 & 13 & Extrarenal & $\begin{array}{l}\text { Cytopenia (Evans } \\
\text { Syndrome) }\end{array}$ & $\mathrm{GC}, \mathrm{HCQ}$ & Non-responder \\
\hline $3, F$ & 29 & 14 & Extrarenal & $\begin{array}{l}\text { Serositis, lymphopaenia, } \\
\text { arthritis }\end{array}$ & $\mathrm{GC}, \mathrm{HCQ}$ & $\begin{array}{l}\text { Complete response at } 6 \\
\text { months }\end{array}$ \\
\hline $4, F$ & 21 & 5 & Extrarenal & $\begin{array}{l}\text { Arthritis, skin rash } \\
\text { Cytopenia }\end{array}$ & $\mathrm{GC}, \mathrm{HCQ}$ & $\begin{array}{l}\text { Complete response at } 3 \\
\text { months }\end{array}$ \\
\hline $5, F$ & 35 & 10 & Extrarenal & Skin vasculitis & $\begin{array}{l}\text { GC, HCQ, MMF, } \\
\text { Belimumab }\end{array}$ & Non-responder \\
\hline $6, F$ & 63 & 3 & Nephritis & Anaemia, serositis & $\mathrm{GC}, \mathrm{HCQ}, \mathrm{MMF}$ & $\begin{array}{l}\text { Complete response at } 3 \\
\text { months }\end{array}$ \\
\hline $7, \mathrm{~F}$ & 32 & 13 & Extrarenal & Arthritis & $\mathrm{GC}, \mathrm{HCQ}, \mathrm{MMF}$ & Partial response at 3 months \\
\hline $8, F$ & 35 & 17 & $\begin{array}{l}\text { Nephritis } \\
\text { neutropaenia }\end{array}$ & Neutropaenia & $\mathrm{GC}, \mathrm{AZA}$ & Partial response at 3 months \\
\hline
\end{tabular}

AZA, azathioprine; GC, glucocorticoids; HCQ, hydroxychloroquine; MMF, mycophenolate mofetil; TAC, Tacrolimus; PGA, physician global assessment. 


\begin{tabular}{|c|c|c|c|c|c|}
\hline Authors & Type of study & $\mathbf{N}$ & Disease manifestations & Primary outcome & Results \\
\hline Tse et $a l^{25}$ & $\begin{array}{l}\text { Retrospective } \\
\text { cohort study }\end{array}$ & 6 & $\begin{array}{l}\text { Membranous/inactive LN } \\
\text { and persistent proteinuria } \\
(>1 \mathrm{~g} / \text { day })+\mathrm{GC}(\leq 0 \mathrm{mg} / \\
\text { day }) \pm \mathrm{AZA} \text { or MMF }\end{array}$ & $\begin{array}{l}\text { Change in } \\
\text { proteinuria/24 hours }\end{array}$ & $\begin{array}{l}\text { Marked reduction of proteinuria by } 50 \% \\
\text { or more. }\end{array}$ \\
\hline $\begin{array}{l}\text { Szeto et } \\
a l^{26}\end{array}$ & $\begin{array}{l}\text { Open-label } \\
\text { study }\end{array}$ & 18 & LN (class V) & $\begin{array}{l}\text { Change in } \\
\text { proteinuria/24 hours } \\
\text { at } 12 \text { and } 24 \text { weeks }\end{array}$ & $\begin{array}{l}\text { TAC safe and effective for pure class } \mathrm{V} \\
\text { LN. Faster resolution of proteinuria and } \\
\text { lower risk of lupus flare within } 1 \text { year, } \\
\text { compared to conventional treatment. }\end{array}$ \\
\hline Yap et $\left.a\right|^{27}$ & $\mathrm{RCT}$ & 16 & $\begin{array}{l}\text { LN (class V) with } \\
\text { nephrotic syndrome }\end{array}$ & $\begin{array}{l}\text { Complete response at } \\
24 \text { months }\end{array}$ & $\begin{array}{l}\text { Both MMF and TAC (+GC) effective } \\
\text { for severe membranous LN. The small } \\
\text { sample size of the cohort precluded } \\
\text { conclusions on the difference in efficacy } \\
\text { between the two drugs. }\end{array}$ \\
\hline
\end{tabular}

AZA, azathioprine; GC, glucocorticoid; LN, lupus nephritis; MMF, mycophenolate mofetil; TAC, Tacrolimus.

The relatively short follow-up period of our case series is another limitation to be acknowledged in our study. Indeed, while efficacy in controlling disease activity has been rapidly demonstrated, a long-term follow-up is crucial to detect drug toxicity.

In conclusion, our data support the role of TAC as a useful immunosuppressive drug, with a high rate of success when added to previous therapy to refractory lupus patients with renal and non-renal disease. The safety profile was also very good, which reinforces a promising role of TAC in the therapeutic armamentarium of SLE.

\section{Author affiliations}

${ }^{1}$ Department of Clinical and Experimental Medicine, Rheumatology Unit, University of Pisa, Pisa, Italy

${ }^{2}$ Centre de référence maladies auto-immunes et systémiques rares de l'île de France, Service de médecine interne Pôle médecine, Hôpital Cochin, AP-HP, Paris, France

${ }^{3}$ Autoimmune Diseases Research Unit, BioCruces, Hospital Universitario Cruces, University of the Basque Country, Barakaldo, Spain

Contributors MM-C, MB, CLO, CS, RV provided a substantial contribution to the collection of the data. MM, GR-I and NC-C designed the study. CT and RV performed the analysis and interpreted the data. EE and CT prepared the draft of the work. All the authors revised it critically and approved the final version.

Funding The authors have not declared a specific grant for this research from any funding agency in the public, commercial or not-for-profit sectors.

Competing interests None declared.

Patient consent Not required.

Ethics approval Comitato Etico di Area Vasta Nord Ovest.

Provenance and peer review Not commissioned; externally peer reviewed.

Data sharing Statement There are not additional unpublished data from the study available.

Open access This is an open access article distributed in accordance with the Creative Commons Attribution Non Commercial (CC BY-NC 4.0) license, which permits others to distribute, remix, adapt, build upon this work non-commercially, and license their derivative works on different terms, provided the original work is properly cited, appropriate credit is given, any changes made indicated, and the use is non-commercial. See: http://creativecommons.org/licenses/by-nc/4.0

\section{REFERENCES}

1. Shrestha BM. Two decades of tacrolimus in renal transplant: basic science and clinical evidences. Exp Clin Transplant 2017;15:1-9.

2. Muduma G, Saunders R, Odeyemi I, et al. Systematic review and meta-analysis of tacrolimus versus ciclosporin as primary immunosuppression after liver transplant. PLoS One 2016;11:e0160421.

3. Song YH, Cai GY, Xiao YF, et al. Efficacy and safety of calcineurin inhibitor treatment for Iga nephropathy: a meta-analysis. BMC Nephrol 2017:18:61.

4. Zhu LB, Liu LL, Yao L, et al. Efficacy and safety of tacrolimus versus cyclophosphamide for primary membranous nephropathy: a metaanalysis. Drugs 2017;77:187-99.

5. Liao R, Liu Q, Zheng Z, et al. Tacrolimus protects podocytes from injury in lupus nephritis partly by stabilizing the cytoskeleton and inhibiting podocyte apoptosis. PLoS One 2015;10:e0132724.

6. Kuhn A, Gensch K, Haust M, et al. Efficacy of tacrolimus $0.1 \%$ ointment in cutaneous lupus erythematosus: a multicenter, randomized, double-blind, vehicle-controlled trial. J Am Acad Dermatol 2011;65:54-64.

7. Mok CC. Calcineurin inhibitors in systemic lupus erythematosus. Best Pract Res Clin Rheumatol 2017;31:429-38.

8. Hannah J, Casian A, D'Cruz D. Tacrolimus use in lupus nephritis: systematic review and meta-analysis. Autoimmun Rev 2016;15:93-101.

9. Miyasaka N, Kawai S, Hashimoto H. Efficacy and safety of tacrolimus for lupus nephritis: a placebo-controlled double-blind multicenter study. Mod Rheumatol 2009;19:606-15.

10. Chen W, Tang X, Liu Q, et al. Short-term outcomes of induction therapy with tacrolimus versus cyclophosphamide for active lupus nephritis: a multicenter randomized clinical trial. Am J Kidney Dis 2011:57:235-44.

11. Wang S, Li X, Qu L, et al. Tacrolimus versus cyclophosphamide as treatment for diffuse proliferative or membranous lupus nephritis: a non-randomized prospective cohort study. Lupus 2012;21:1025-35.

12. Li X, Ren H, Zhang Q, et al. Mycophenolate mofetil or tacrolimus compared with intravenous cyclophosphamide in the induction treatment for active lupus nephritis. Nephrol Dial Transplant 2012;27:1467-72.

13. Mok CC, Ying KY, Yim CW, et al. Tacrolimus versus mycophenolate mofetil for induction therapy of lupus nephritis: a randomised controlled trial and long-term follow-up. Ann Rheum Dis 2016;75:30-6.

14. Kamanamool N, Ingsathit A, Rattanasiri S, et al. Comparison of disease activity between tacrolimus and mycophenolate mofetil in lupus nephritis: a randomized controlled trial. Lupus 2018;27:647-56.

15. Uchino A, Tsukamoto $\mathrm{H}$, Nakashima $\mathrm{H}$, et al. Tacrolimus is effective for lupus nephritis patients with persistent proteinuria. Clin Exp Rheumatol 2010;28:6-12.

16. Lee T, Oh KH, Joo KW, et al. Tacrolimus is an alternative therapeutic option for the treatment of refractory lupus nephritis. Lupus 2010;19:974-80.

17. Fei $Y$, Wu $Q$, Zhang $W$, et al. Low-dose tacrolimus in treating lupus nephritis refractory to cyclophosphamide: a prospective cohort study. Clin Exp Rheumatol 2013;31:62-8. 
18. Gordon S, Denunzio T, Uy A. Success using tacrolimus in patients with proliferative and membranous lupus nephritis and refractory proteinuria. Hawaii J Med Public Health 2013;72(Suppl 4):18-23.

19. Lanata CM, Mahmood T, Fine DM, et al. Combination therapy of mycophenolate mofetil and tacrolimus in lupus nephritis. Lupus 2010;19:935-40.

20. Bertsias GK, Tektonidou M, Amoura Z, et al. Joint european league against rheumatism and european renal associationeuropean dialysis and transplant association (EULAR/ERA-EDTA) recommendations for the management of adult and paediatric lupus nephritis. Ann Rheum Dis 2012;71:1771-82.

21. Appel GB, Contreras G, Dooley MA, et al. Mycophenolate mofetil versus cyclophosphamide for induction treatment of lupus nephritis. J Am Soc Nephrol 2009;20:1103-12.

22. Bao H, Liu ZH, Xie HL, et al. Successful treatment of class V+IV lupus nephritis with multitarget therapy. J Am Soc Nephrol 2008;19:2001-10.

23. Liu Z, Zhang H, Liu Z, et al. Multitarget therapy for induction treatment of lupus nephritis: a randomized trial. Ann Intern Med 2015;162:18-26.

24. Sakai R, Kurasawa T, Nishi E, et al. Efficacy and safety of multitarget therapy with cyclophosphamide and tacrolimus for lupus nephritis: a prospective, single-arm, single-centre, open label pilot study in Japan. Lupus 2018;27:273-82.

25. Tse KC, Lam MF, Tang SC, et al. A pilot study on tacrolimus treatment in membranous or quiescent lupus nephritis with proteinuria resistant to angiotensin inhibition or blockade. Lupus 2007;16:46-51.

26. Szeto CC, Kwan BC, Lai FM, et al. Tacrolimus for the treatment of systemic lupus erythematosus with pure class $v$ nephritis. Rheumatology 2008;47:1678-81.

27. Yap DY, Ma MK, Mok MM, et al. Long-term data on tacrolimus treatment in lupus nephritis. Rheumatology 2014;53:2232-7.

28. Singh JA, Hossain A, Kotb A, et al. Risk of serious infections with immunosuppressive drugs and glucocorticoids for lupus nephritis: a systematic review and network meta-analysis. BMC Med 2016;14:137.

29. Suzuki K, Kameda H, Amano K, et al. Single center prospective study of tacrolimus efficacy and safety in the treatment of various manifestations in systemic lupus erythematosus. Rheumatol Int 2011;31:757-63.

30. Watanabe H, Yamanaka R, Sada KE, et al. The efficacy of addon tacrolimus for minor flare in patients with systemic lupus erythematosus: a retrospective study. Lupus 2016;25:54-60.

31. Li Y, Feng $X$. Efficacy and safety of tacrolimus in systemic lupus erythematosus patients with refractory thrombocytopenia: a retrospective study. Lupus 2018;27:60-5. 